PESSOAL

\title{
Como Aperfeiçoar o Sistema de Carreiras no Serviço Público
}

Conferência pronunciada por James C. Worthy, ${ }^{\star}{ }^{*}$ em reunião antual da Sociedade de Administração de Pessoal.

Tradução de Mary Cardoso

$\mathrm{N}$

AS minhas atuais andanças pela capital, tenho ouvido falar muito na situação da carreira pública sob a nova administração. Muito daquilo que tenho ouvido é dito em tom apreensivo, e parece haver em muitos setores o sincero temor de que algumas das ações e, em particular, algumas das atitudes de certos elementos-chaves possam contribuir, intencionalmente ou não, para minar o conceito de carreira e, talvez, possibilitar um recuo no sentido dos males do nepotismo. Em minha opinião, tal receio é totalmente infundado.

Mas, infundado ou não, é perfeitamente natural e compreensivel a existência de semelhante preocupação, pois qualquer alteração na liderança traz perturbações ao longo de tôda a hierarquia e quanto mais alto, na estrutura da organização, ocorrerem as mudanças, tanto mais ampla é a área de perturbaçã́o. $\mathrm{E}$ isso não é um fato que se limite apenas ao campo político; ocorre igualmente nas organizações industriais, do mesmo modo que, presumo, nas instituições educacionais e religiosas e em tôdas as demais formas de organização humana - inclusive, permitam-me observar, a família.

Estudos interessantes dêsse fenômeno foram feitos pelo Departamento de Pessoal da Sears, Roebuck \& Cia., chegands à conclusão de que, seja qual for a razão que determine a substituição

(*) James C. Worthy, Secretário-Adjunto de Administração, no Departamento de Comércio. Assumiu êsse pôsto em maio de 1953, depois de quinze anos de atividade na Sears, Roebuck \& Cia., durante os quais serviu, a partir de 1950, como Diretor de Relações de Trabalho. Sua experiência anterior no Serviço Público incluiu vários cargos na Administração da Reconstrução Nacional, de 1933 a 1936. Escreve muito para revistas especializadas de pessoal e é o autor da recente obra «Men, Management and Organization», sendo amplamente conhecido nos circulos técnicos de administração pela pesquisa que dirigiu na Sears, Roebuck. 
de um gerente de loja, o pessoal que com êle trabalhava levará tempo considerável para se acostumar com a mudança. Quando, por exemplo, ocorre a promoção de um gerente capaz e estimado por seus auxiliares, o outro que o substitui, simplesmente porque é diferente e tem sua maneira própria de trabalhar, vai fatalmente enfrentar constantes comparações com seu antecessor, muitas vêzes levando a pior. Se acontece que um homem pouco competente é substituido por um outro gerente, cuja missão é pôr as coisas nos eixos ou dar solução a uma conjuntura difícil, o nôvo chefe se vê na contingência de usar pressões a que seus auxiliares não estão habituados, ou de recorrer a ações disciplinares, ou ainda de tomar a iniciativa de mudanças nem sempre agradáveis e às quais os subordinados reagem desfavoràvelmente.

As pesquisas feitas na Sears mostram que qualquer alteração na chefia das lojas exige uma série de ajustamentos da parte do resto do pessoal do setor atingido, dependendo a extensão dêsse ajustamento e o grau de perturbação dêle decorrente das circunstâncias de cada caso individual. Os empregados têm que aprender a trabalhar com o nôvo chefe, precisam se adaptar a sua maneira de fazer as coisas, devem aprender o significado real de suas ações. E, acima de tudo, o nôvo gerente e seus auxiliares têm que se conhecer bem uns aos outros, de modo tal que permita o estabelecimento das atitudes de confiança e respeito mútuos que são essenciais ao bom trabalho em equipe e à boa cooperação. Tudo isso toma tempo e não pode ser conseguid’ da noite para o dia. E até que o processo de reajustamento tenha atingido um ponto determinado, é inevitável que haja receio e preocupação.

Se uma coisa dessas acontece quando se trata apenas de mudar um gerente de loja, com muito mais razão acontecerá e com a conseqüência de muito mais amplas perturbações - quando um nôvo partido e um grupo inteiramente nôvo de pessoas tomam as rédeas do Govêrno. Os ajustamentos que nesse caso se fazem necessários serão evidentemente muitíssimo maiores, em particular porque os recém-chegados diferem extremamente de seus antecessores, em muitas e fundamentais questões de politica de govêrno.

Uma dessas questões diz respeito às medidas de economia. A nova administração pretende efetuar considerável redução nas despesas federais, o que significa sensivel redução em pessoal. Os cortes de funcionários são sempre medidas penosas, principalmente para os atingidos por elas e para os que passam a temer os novos cortes. Nessas condições, compreende-se fàcilmente porque é que há tão generalizada preocupação quanto ao futuro do sistema de carreiras, tão importante para a segurança pessoal de muitos milhares de empregados do Estado.

Sei que posso falar pelo Departamento de Comércio e acho que posso falar também por tôda a nova administração ao afir- 
mar, categòricamente, que muito ao contrário do enfraquecimento do sistema de carreiras, um dos nossos principais objetivos é o seu fortalecimento e aperfeiçoamento. E isso não é apenas por uma questão de idealismo, embora o ideal.smo tenha muito que ver com tal orientação. Há pelo menos dois outros fatôres na motivação do interêsse da nova administração pela integridade e eficácia do sistema de carreiras: (1) a própria mentalidade dos membros da nova administração e (2) as exigências de uma administração sadia e eficiente.

É significativo que tantas importantes figuras do nôvo Giovêrno sejam homens de negócios e militares. Êsses dois tipos profissionais costumam ser definitivamente homens de carreira nas respectivas armas ou em seus estabelecimentos comerciais. Estão acostumados a pensar em têrmos de carreira e, em suas próprias organizações, contribuíram provàvelmente, de uma forma ou de outra, para desenvolver e fortalecer um sistema de carre ras, seja qual for a denominação que lhe tenham dado. As assumirem suas novas responsabilidades no Govêrno, é apenas natural que tragam consigo e tratem de aplicar no serviço do Estado os mesmos padrões mentais que desenvolveram em sua exper ência anteriır. Não serão homens dessa espécie que irão destruir o sistema de carreiras; são, antes, do tipo que já está procurando os meios e modos de melhorá-lo.

Uma razão para isso está em que, sendo administradores capazes e experientes, têm aguda percepção da importância da organização e da necessidade de contar com gente competente em todos os niveis da escala hierárquica. Têm também plena consciência do fato de que a competência não é apenas uma questão de qualificação técnica, que uma unidade de trabalho pode ser composta de pessoal da mais alta capacidade indivi lual mas que, a menos que êsse grupo saiba trabalhar, como uma equipe, como um todo coordenado, o resultado final de seus esforços pode deixar muito a desejar. Tudo isso mostra bem a tremenda significação da estabilidade, pois é necessário tempo para que se consiga urdir a trama complexa das relações pessoais, capazes de gerar o esfôrço da cooperação. Sem que exista um vigoroso sistema de carreiras, é impossível essa tão essencial estabilidade.

Para além dessa certeza, repousa o fato de que os membros do nôvo grupo conhecem, por experiência própria, a importância da organização. Sabem que não podem desempenhar suas tarefas apenas com o enunciado de diretrizes ou ordens administrativas. Sabem que precisam de facilidades e de meios que só a organização dá, para que as suas ordens e diretrizes sejam cumpridas. E sabem também que os elementos com que operam não constituem peças de mecanismos que respondam instantânea e automàticamente a seus desejos, mas são sêres humanos, cheios de aspirações e necessidades, que devem ser levadas em conta, para 
que a administração possa alcançar seus objetivos. E, finalmente, sabem ainda que duas das mais importantes dessas necessidades e aspirações são um grau razoável de segurança e uma razoável oportunidade de progresso, os quais dependem, em bem ampla escala, de um verda leiro sistema de carreiras.

Repetindo, podemos dizer que homens que conhecem essas coisas por experiência própria, homens que são de fato excelentes administradores, cidadãos dedicados, cujo objetivo é servir à própria pátria, dirigindo essa vasta e complexa máquina administrativa com o máximo de eficiência e economia - não são homens para minar e destruir o sistema de carreiras; ao contrário, vêm nesse sistema, dinamizado e revitalizado. um dos fatôres necessários à consecução dos objetivos que pretendem alcançar.

Entretanto, a idéia de revigurar o sistema de carreiras não é uma descoberta da nova administração, pois poucos são os problemas nacionais que têm recebido, como êsse, tão cuidadosa e continua atenção. Lembro-me sem dificuldade de alguns exemplos dessa atenção: o relatório da Comissão Presidencial sôbre Gerência Administrativa, o relatório da Comissão Hoover sôbre Administração do Pessoal, e o excelente relatório da Subcomissão do Senado sôbre Políticas de Mão de Obra, publicado em março do corrente ano sob o $\mathrm{n}^{\circ} 37$. Os grupos responsáveis pelas investigações em que se basearam tais relatórios pesquisaram exaustivamente todos os múltiplos aspectos do problema e acredito que, no conjunto, as recomendações que ofereceram constituem pelo menos uma base para um programa realista visando a) aperfeiçoamento do sistema de carreiras. Não haverá propósito em tentar recapitular aqui as conclusões dêsses e de outros estudos. Nem tampouco tentar resumir numa conclusão só tudo aquilo que deve ser feito para fortalecer o sistema; nessa matéria os senhores sabem bem mais do que eu e, como amador, repugna-me debater questôes técnicas com especialistas. Posso, talvez, porém ser útil se lhes disser das minhas primeiras reações, como recém-chegado às áreas do Govêrno, e se sugerir quatro importantes tópicos que, no meu entender, estão exigindo especial atenção:

19) o problema do recrutamento de pessoal qualificado para o serviço de carreira;

$\left.2^{\circ}\right)$ a necessiłade de padrões de compensação mais realistas, particularmente nos niveis mais elevados;

3) a necessidade de programas eficazes de aperfeiçoamento de chefes e, finalmente,

$4^{\circ}$ ) a importância que há em que os próprios funcionários de carreira reconheçam e aceitem a responsabilidade que cabe a cada um no aperfe:çoamento do sistema. 
Permitam-me repetir que não são essas as únicas áreas que reclamam atenção, mas para mim são importantíssimas. Vamos considerá-las, na ordem devida.

Do ponto de vista da lógica e da seqüência natural dos fatos, o primeiro tópico a considerar é a forma pela qual é feito o recrutamento de pessoal para o serviço público. Da mesma maneira que um rio não se poderá sobrepor à sua fonte, assim também a carreira pública nunca poderá ser melhor do que os funcionários que rela ingressam. Infelizmente, praticamos um sistema de seleção extremamente inadequado e é uma coisa espantosa que os órgãos do Govêrno consigam, ainda assim, obter os bons funcionários que obtêm - e vai nessa observação antes de tudo um tributo ao valor pessoal dos senhores; de modo algum um tributo ao sistema sob o qual têm que trabalhar.

Mais uma vez, não tentarei documentar aqui um capítulo sôbre o qual os senhores sabem muito mais do que eu, mas gostaria de comentar dois aspectos: a necessidade de muito maior descentralização das atividades de seleção, mesmo além do que foi sugerido pelo relatório Hosver e por outros inquéritos, e a ilusão essencial que caracteriza o sistema de concursos. Sei muito bem que, abordando êsses dois pontos, me aventuro por terreno perigoso, mas quero-lhes dizer o que penso a respeito.

No que se refere à descentralização, fico realmente horrorizado ante o espetáculo que oferece a tentativa de centralizar qualquer fase do processo de recrutamento para um complexo federal que inclui dois milhões e quinhentos mil funcionários. Se estivéssemos comprando metralhadoras, máquinas de escrever ou móveis de escritório, um pouco de centralização teria sentido. Mas estamos tentando encontrar sêres humanos para tarefas especificas, e nem as pessoas, nem as tarefas, são padronizadas. Embora certos grupos de pessoas possam ter determinadas características em comum - tais como idade, educação, etc. não há como fazê-los caber em moldes exatamente iguais. E, embora certos trabalhos possam ter alguns caracteristicos iguais inclusive as denominações - apresentam, êles também, variações infinitas. Para que o máximo de rendimento possa ser obtido, é essencial que a responsabilidade da seleção e do enquadramento esteja estreitamente vinculada à unidade de trabalho interessada. Sómente assim serão possíveis a determinação inteligente das necessidades de pessoal, o desenvolvimento de adequados programas de recrutamento e o estabelecimento da exata adequação das inconfundíveis características individuais dos sêres humanos aos inconfundiveis requisitos de cada cargo.

Não posso deixar de voltar, a esta altura, à minha experiên cia na Sears, Roebuck \& Cia. A Sears não é, naturalmente, tão grande quanto o Govêrno Federal, mas, com os seus 219.000 empregados, é consideràvelmente maior do que grande parte dos 
departamentos federais. Nessa emprêsa, a responsabilidade da seleção e do enquadramento cabe, ùnicamente, a cada unidade local de trabalho - quer se trate de loja de varejo, do setor de encomendas postais, da fábrica ou de outro ramo qualquer Mesmo quando várias lojas estão localizadas numa miesma comunidade - há quatro, na área metropolitana de Washington - cada loja faz o seu próprio recrutamento. $\mathrm{E}$ isso, atente-se, para tipos de trabalho de extrema comparabilidade, de fato muito mais semelhantes entre si do que os que se podem identificar em diferentes departamentos oficiais, ou entre diferentes divisões de um mesmo departamento. A política que assim segue a Sears é a mesma que se observa na indústria em geral.

Assim sendo, não me parece bastante a simples adoção de uma das recomendações da Comissão Hoover, e de outros grupos especializados, no sentido de que seja descentralizado o recrutamento para tarefas especiais e que o recrutamento para encargos comuns continue a ser feito pela Comissão do Serviço Civil. Esta recomendação - que acredito tenha sido em substância adotada - é boa até certo ponto, mas êsse ponto ainda fica muito aquém do necessário. Até que possamos dar outro passo adiante, no sentido de fazer cada órgão realmente responsável por todo o processo de recrutamento e seleção de que tem necessidade - é claro que dentro de padrões e diretrizes fixados pela Comissão - continuaremos a sentir o pêso morto de uma infindável burocracia e, mais importante ainda, seremos incapazes de solucionar o problema do aperfeiçoamento da seleção de pessoal para as carreiras do Estado.

O segundo ponto que quero acentuar quanto ao recrutamento é o da ilusão essencial do sistema competitivo utilizado. Sei que estou me arriscando muito neste terreno mas, apesar disso, devo dizer que acho muito significativo o fato de que, no vastíssimo campo da indústria particular dêste país, nenhumı uso se faça, pràticamente, do sistema de exames tal como se desenvolveu e é aplicado pelo Govêrno Federal. Acho que se tal sistema tivesse valor - mesmo limitado - seria uma conclusão axiomática que a indústria privada, com sua grande flexibilidade e não menor liberdade de ação, o deveria estar usando muito mais do que o faz.

A grande ilusão estriba-se, certamente, na conviç̧ão de que é possivel prever o desempenho de uma dada tarefa ante o que ficar demonstrado pelo comportamento diante de determinado tipo de exame. Pode ser que seja possivel isolar certos elementos de alguns tipos de trabalho e, de algum modo, traduzi-los numa fórmula de exame, mas em caso algum, com exceção talvez dos mais simples, mais repetitivos tipos de trabalho, se conseguirá incorporar todos êsses elementos num molde, através do qual medir a competência necessária a uma completa configuração de aptidóes e características que são essenciais ao sucesso no traba- 
lho. O documento $n^{9} 37$, do Senado, a que já fiz referência aqui, assinala excelentemente êsse particular.

No que se refere a exames versus entrevistas. há uma curiosa inversão de práticas entre a indústria e o Govêrno. $\mathrm{Na}$ indústria usam-se muito pouco os exames, seja qual fôr seu tipo. Mesmo nas áreas em que se usam bastante os testes psicológicos, como na Sears, por exemplo, faz-se o máximo para manter os testes subordinados às entrevistas. No Govêrno faz-se exatamente o oposto e nas práticas de exame nota-se forte preconceito contra quaisquer formas de entrevista.

Compreendo bem a razão disso. Esse preconceito representa um esfôrço para a eliminação do favoritismo, politico ou de outra natureza, e visa a colocar a seleção na base mais objetiva possível. Mas acho que assim estamos pagando um preço tremendo pelo que estamos tentando obter. Nos nossos esforços para eliminar o favoritismo, deliberadamente excluímos de qualquer consideração as coisas mais importantes a respeito das pessoas, aquelas que nunca podem ser medidas objetivamente e que só podem ser determinadas com alguma precisão por hábeis e experimentados entrevistadores, que tenham oportunidade de avaliar pessoalmente as habilidades e potencialidades de cada candidato.

Temos que confiar mais - e não que duvidar - na visão e no discernimento dos responsáveis pelo julgamento das qualificações daqueles que buscam emprêgo nas carreiras do Govêrno. O esfôrço para eliminar ou para minimizar o elemento pessoal só nos pode conduzir a um beco sem saída - exatamente onde estamos hoje. O fato de se dar mais liberdade e confiança ao julgamento direto não significa, necessàriamente, que se vá abrir a caixa de Pandora do sistema do nepotismo. Muito ao contrário, pode acarretar para êsse julgamento uma objetividade muito maior do que o precário sentido pelo qual lutamos agora, melhorando assim enormemente a qualidade da seleção de funcionários para o serviço federal.

Mesmo com aperfeiçoamento considerável de nossos métodos atuais de seleção, a qualidade dos quadros federais ficará dependendo, em larga escala, da qualidade dos elementos que forem atraídos para os cargos públicos, bem como dos atributos pessoais daqueles que, uma vez admitidos, se sentirem desejosos de continuar a serviço do Estado. Não há dúvida, nesse particular, de que as escalas de pagamento não são o único fator que conta, mas não se poderá negar que são de enorme importância.

$\mathrm{E}$ aqui encontramos uma situação curiosa. Em grande proporção, os níveis salariais dos escalões médios e inferiores dos quadros do Govêrno ganham em comparação com os que prevalecem na indústria particular, às vêzes de forma altamente desvantajosa para a classe patronal. Mas, nos escalões mais eleva- 
dos, os niveis de pagamento do Govêrno, seja qual fôr o critério de medida que se prefira empregar, são dolorosamente inadequados e não só se têm mantido assim por longo tempo, como ùltimamente têm tido cada vez mais acentuada essa inadequação.

A Comissão Hoover assinalou em seu relatório que, enquanto nos niveis inferiores das escalas, os quantitativos se tinham elevado de 43 a $56 \%$, no escalão superior o aumento tinha sido de apenas $15 \%$. Na indústria, houve acentuada tendência no sentido de um aumento mais rápido dos salários da massa, em comparação com os dos chefes, mas as taxas relativas de crescimento dos dois grupos foram muito mais equilibrados nesse campo do que no setor do Govêrno.

O estabelecimento dos chamados cargos de cúpula representou um esfôrço no sentido da correção parcial do problema, que, entretanto, não passou de modestos começos. Em todo o serviço fe leral há apenas quatrocentos cargos de cúpula de caráter permanente (com exceção de um ou outro caso isolado, resultante de legislação específica), o que quer dizer que num quadro geral de cêrca de 2.500 .000 funcionários federais apenas $0,016 \%$ ganham igual ou acima de doze mil dólares por ano. A percentagem comparável na Sears, Roebuck é dado confidencial, mas posso-lhes assegurar que é bem maior do que essa, como é bem maior em quase tôdas as emprêsas privadas, qualquer que seja sua envergadura.

E não é apenas o número de pessoas colocadas no nível máximo de remuneração que é indevidamente limitado; a diferença entre os salários pagos aos niveis inferiores e aquêles atribuídos aos niveis mais altos e também extremamente pequena. Como homem de negócios, acho quase inaceitável uma situação em que os funcionários de carreira que atingiram os cargos mais difíceis e de maior responsabilidade no Serviço Público percebem pouco mais do que três vêzes aquilo que ganha o escriturário mais humilde, ou um simples mensageiro.

Tenho plena consciência de alguns dos fatôres que levaram a essa situação e, particularmente, admito que de um ponto de vista prático qualquer correção deverá aguardar o aumento salarial dos membros de outros grupos, especialmente do Legislativo. Mas o fato é que deve haver igual necessidade de completa revisão salarial para Deputados e Senadores e espero, com ansiedade, que o problema da remuneração ao pessoal de cúpula do Govêrno - quer se trate do Legislativo, quer do Executivo, quer do Judiciário - seja em seu conjunto encarado com franqueza e resolvido com coragem.

A correção dêsse problema não implica, necessàriamente, nem precisa implicar, em aumento algum nas despesas federais. Os homens de negócio pagam a seus chefes como pagamı porque consideram isso um bom negócio e não há razão pela qual o Govêr- 
no assim também não considere o assunto. A indústria descobriu, há muito tempo, que teria que entrar em competição para encontrar gente boa $e$ que as grandes somas de dinheiro que gasta para isso são mais do que compensadas por maior capacidade e maior habilidade. Precisamos pagar, pelos altos cargos do Govêrno, salários que atraiam e retenham as pessoas mais qualificadas que o país possa oferecer e, como país, isso é o mínimo que podemos admitir. Não estou sugerindo que alcancemos exatamente as mesmas cifras da indústria em matéria de salários de chefes, já que o Govêrno pode oferecer muitos incentivos e conveniências que nem sempre podem ser igualados por aquela, mas nossas atuais politicas, nesse particular, não têm base na realidade e devemos tomar atitudes radicais para corrigi-las.

O terceiro dos principais requisitos para melhorar o sistema de carreiras, e sôbre o qual quero ainda falar agora, é a necessidade de um mais adequado programa de aperfeiçoamento de chefes. Muito tem sido escrito e falado a êsse respeito e tomaram-se mesmo algumas medidas nessa direção, mas até aqui a ação - e muito da racionalização - desenvolvida tem sido extremamente inadequada em têrmos de necessidades reais.

As pessoas progridem no serviço do Govêrno e há muitos exemplos de gente que começou nos postos mais humildes e que alcançou posições do maior destaque e responsabilidade. Mas quando isso aconteceu, o fator acidental foi muito importante e o progresso dependeu sobretudo da iniciativa e engenhosidade - e daquilo que eufemisticamente se define como «bons contatos»dos próprios indivíduos interessados. Em caso algum resultou de um programa racional ou de um plano deliberado.

Entre outros fatôres que podem ser citados, acho que há duas razões importantes para que se tenha feito tão pouco progresso: primeiro, a convicção de que a iniciativa repousa, largamente, na Comissão do Serviço Civil e, segundo, uma concentração exagerada em métodos formais de treinamento. Seja-me permitido dizer algumas palavras a êsse respeito.

E verdade que cabem por lei à Comissão do Serviço Civil responsabilidades definidas nessa matéria. Mas, enquanto êsse órgão pode dar certa assistência e orientação técnicas - e exercer certa liderança - no assunto, não teremos nada comparável a um programa prático e eficaz de aperfeiçoamento de chefes no Serviço Civil até e a menos que a ação necessária seja de iniciativa de cada departamento. Posso dizer, a propósito, que no Departamento de Comércio estamos dando cumprimento a um programa que consideramos adaptado às nossas necessidades. É prematuro divulgar minúcias dêsse projeto, porém aquêles que o estão executando o acham bom e adequado, e acreditam que nos dará os resultados que desejamos. Trabalharemos, naturalmente, em 
estreita coordenação com a Comissão do Serviço Civil e, na verdade, esperamos que a mesma considere o Departamento como um laboratório e que de nossa experiência retire orientação para seu trabalho e para o de outros órgãos do Govêrno. A única coisa que quero deixar bem clara aqui é o fato de que qualquer bom programa de aperfeiçoamento de pessoal tem que brotar diretamente das necessidades e características de cada órgão e para isso é necessário que a iniciativa caiba, em larga escala, a êsses mesmos órgãos e não a um órgão central.

Outra importante razão para o progresso relativamente lento que se fêz nos serviços do Govêrno em matéria de aperfeiçoamento, foi a certeza, mais ou menos implicita, de que o programa a cumprir deve ser formal; de que deve envolver amplo uso de salas de aula, de conferência e de outras técnicas semelhantes; de que deve ficar registrado em algum tipo de manual e constituir responsabilidade de um técnico de treinamento.

Acho que tudo isso está errado e, mais uma vez, estribo-me aqui no que conheço da indústria privada. Se o mundo dos negócios dependesse de métodos formais de treinamento, ou não haveria negócios ou o custo de sua promoção seria infinitamente maior do que é hoje. O mesmo pode ser dito do Govêrno. No setor público, tanto quanto nos negócios, a maioria das pessoas aprende a trabalhar e se prepara para mais altas responsabilidades sobretudo através da experiência e porque tomam, elas próprias, a iniciativa, de modo a obterem o máximo do tipo de experiência que conseguem reunir. Isso não quer dizer que o treinamento em geral e o aperfeiçoamento de chefes em particular devam constituir um processo desorganizado e deixado ao acaso. Muito ao contrário, já que sòmente através de adequada organização é possivel obter um resultado consistentemente eficiente. Mas, em vez de dedicar um tempo enorme à aplicação e ao aperfeiçoamento de técnicas formais, que são acima de tudo essencialmente artificiais, deveríamos devotar maiores esforços no sentido de aprender como organizar e usar melhor as técnicas naturais informais, já em operação e cujo potencial seria tremendamente aumentado se fossem usadas com propriedade.

Como já disse, é um pouco cedo para falar muito sôbre o que pretendemos fazer no Departamento de Comércio: Mas posso dizer que, enquanto nossos planos serão cuidadosamente elaborados, nossos métodos procurarão fazer êsse teste de naturalidade e informalidade. Farão também um teste de economia, porque, estando estreitamente vinculados ao próprio trabalho da organização, exigirão muito pouca despesa extraordinária. Sinto-me tentado a afirmar que qualquer programa dêsses, que exija mais do que um minimo de operadores e um mínimo de despesas, não poderá ser, de fato, um bom programa.

Há ainda um outro ponto que quero acentuar: a responsabilidade pessoal de cada integrante das carreiras públicas no sen- 
tido de dar sua própria contribuição para o aperfeiçoamento do sistema de carreiras. Não é bastante que os membros da nova administração reconheçam a responsabilidade que lhes cabe, pois a menos que os profissionais do Serviço Público carreguem a sua parcela dessa responsabilidade, nenhum grande progresso psderá ser feito.

Os Governos vêm e vão - mas o Serviço Público persiste. Mesmo sòmente por uma questão de interêsse pessoal - somado, é claro, às superiores considerações da ampla política nacional, que tradicionalmente tem constituído o campo de especial interêsse dos servidores públicos - os funcionários de carreira têm obrigação de fazer o máximo que puderem para fortalecer o sistema e o conceito da carreira pública.

Isso pode ser feito de muitas formas e uma delas é deixar de lado, ou pelo menos minimizar, as desvantagens, e às vêzes as indignidades, a que tão freqüentemente se vêem sujeitos os servidores do Estado. Não é minha intenção negar algumas das coisas pouco agradáveis, que essa classe tem que aceitar. Sei que se nos quisermos ocupar com elas, poderemos organizar uma longa lista de queixas e reclamações. Mas se nos concentrarmos no lado negativo, tenderemos a descurar ou a prejudicar o positivo. Todo trabalho tem suas vantagens e suas desvantagens e a definição de umas e outras difere um pouco do Governo para a indústria particular, mas estou certo de que há diferenças maiores entre diversos departamentos do Estado e diferentes emprêsas industriais particulares, do que entre o Govêrno e a indústria como um todo.

Façamos tudo o que estiver em nosso poder para corrigir as coisas que no Serviço Público precisam ser corrigidas. Mas, por outro lado. mantenhamos os fatôres em sua exata perspectiva e não deixemos que a consciência de alguns dos inconvenientes a que estamos sujeitos nos tornem cegos para o tremendo desafio e para a excepcional oportunidade que, tão acentuadamente, caracterizam a carre ra pública.

O segundo aspecto de grande responsabilidade do funcionário de carreira para o sistema em que se integra envolve a assistência que êle pode prestar à nova administração, na tarefa de tomar as rédeas do Govêrno, dando integral apoio e cooperação às diretrizes politicas que aquela vier a traçar. Qualquer funcionário de carreira, que se sentir em posição antagônica à nova administração e à nova maneira de encarar os problemas nacionais, tem para com o seu próprio serviço, pelo menos, a obrigação de se afastar e de deixar que seu lugar seja ocupado por alguma outra pessoa em quem a nova administração possa confiar e de quem possa obter entusiástico e total apoio. Nesse particular, posso dizer que estou pessoalmente convencido de que a grande maioria dos funcionários de carreira está desejosa - e mesmo 
ansiosa - de apoiar qualquer política e qualquer programa que a nova administração decida aplicar. Mas há alguns que apenas não acreditam em tais coisas, mas que a elas se mostram francamente hostis. Essas pessoas, se continuarem em suas atuais posições e se agirem de forma a comprometer os esforços dos novos dirigentes, não só servirão de obstáculo ao trabalho da nova administração, como farão um mal incalculável ao próprio sistema de carreiras.

Quero assegurar-lhes que nenhum sistema dêsse tipo poderá sobreviver por muito tempo a uma situação em que um nôvo grupo político se vê na impossibilidade de confiar na organização permanente herdada de seus antecessores. O sistema de carreiras deve estar acima da política e isso não só quer dizer que deve estar protegido contra os ataques de origem partidarista, mas também significa que deve dar o mais leal apoio à politica de qualquer partido a que o povo americano tenha entregue a chefia do Govêrno. Repito que o maior prejuizo que um funcionário de carreira pode causar a seu grupo consiste em não aceitar a liderança e, conseqüentemente, em se negar ao cumprimento das diretrizes da nova administração. Essa atitude fere a essência mesma do sistema e todos aquêles que se interessarem em preservá-lo saberão como se comportar em tais circunstâncias.

Terminando, gostaria de assinalar o fato evidente de que a nova equipe depende profundamente dos funcionários de carreira. O sucesso ou insucesso de seus esforços depende muito do grau de cooperação que venha a receber e do desejo dos funcionários não apenas de aceitar passivamente direção e orientação, mas de cooperar de maneira ativa na formulação de políticas, como na assistência aos novos chefes, familiarizando-os com as minúcias e os riscos implicitos nos cargos que se decidiram a exercer.

O segrêdo de um melhor sistema de carreiras está no trabalho de equipe, em que tanto oportunidade como dever são fatôres vitais. Os resultados serão compensadores para todos os que acreditam sinceramente que quem exerce o serviço público é depositário da confiança do povo.

(In «Personnel Administration (Administração de Pessoal)»; vol. 16, n, págs. 1 e segs.) 